Volume-VI, Number-01, January-June, 2011

\title{
Customers' Attitude towards Wireless Internet Services in Bangladesh: An Empirical Study Comparing WIMAX Based and EDGE/EVDO Based Internet Service
}

\author{
S.M. MONIRUL ISLAM* \\ BULBUL AHAMED ${ }^{* *}$
}

\begin{abstract}
This study is an attempt to measure the attitude of customers towards the wireless Internet services in Bangladesh based on the Mertin Fishbein's multi attribute attitude model. Some salient attributes (i.e., speed, bandwidth fluctuation rate) of WIMAX based and EDGE/EVDO based Internet services that affect the attitude of the customers have been selected which customers emphasizes to take purchase-decision as well as usage continuation decision. Two types of wireless Internet service providers (WIMAX and EDGE/EVDO) and ten salient attributes have been considered for this study. It has been found from the study that customers form more positive attitude towards WIMAX based Internet service than EDGE/EVDO based service. Observed differences in mean attitude of different attributes for the two categories of wireless Internet services are measured through Z-test to test the significance of those differences. Findings of this study may be used as an index by the Internet service providers for improvement of their services to satisfy the customers.
\end{abstract}

Key words: Wireless Internet, Customer Attitude, WIMAX, EDGE, EVDO

\section{INTRODUCTION}

Communication is the fundamental need of human beings. From the early evolution of civilization man has invented various means to communicate with others especially with one who is far away geographically. With the expansion of business operations in the world and the trend of human migration, a rapid communication solution became urgency. Internet-based communication system

\footnotetext{
*Senior Lecturer in Marketing, Department of Business Administration, Northern University Bangladesh (NUB), Khulna.

** Senior Lecturer in CSE, Department of Computer Science \& Engineering, Northern University Bangladesh (NUB), Dhaka.
} 
has successfully solved the communication problem with its multiple applications and its use in various dimensions. Internet is now not only the means of communication but also the warehouse of data (i.e. online database), media of promotion (Web advertising), virtual market (i.e. ebay, amazon), means of service distribution to end-users (i.e. online banking, online newspapers), mode of entertainment (i.e. online games, movie, music), virtual community (i.e. blogging, facebook, twitter), and many more. Now, $28.7 \%$ of the world population is Internet user. In Bangladesh the number of Internet users as in August 2010 is about one million which is only $0.6 \%$ of the total population. Though the ratio of Internet users against the population is very low but its significant growth over the last 10 years is remarkable, which is about $500 \%$.

The history of Internet is not old in Bangladesh as in other developing countries or even in developed countries. The Internet operation in Bangladesh started on June 4, 1996 through subscribing the VSAT (Very Small Aperture Terminal) data circuit by the Government of Bangladesh. Telecommunication infrastructure is the base of Internet service dissemination. With the evolution of mobile telecommunication system, wireless Internet, a new horizon of Internet service, was enlightened. Now the Internet users want portable service as they can use it from anywhere else even when they are moving. Now in Bangladesh six mobile telephone operators are functioning and each of them is providing wireless Internet services: Grameen Phone Limited (GP), Orascom Telecom Limited (Banglalink), Pacific Bangladesh Telecom Limited (Citycell), Axiata Bangladesh Limited (Robi), Airtel Bangladesh Limited and Teletalk Bangladesh Limited. These six operators provide EDGE (Enhanced Data rate for GSM Evolution) or EVDO (Evolution Data Optimized) technology based wireless Internet service. Recently a new dimension of wireless Internet service WIMAX (Worldwide Interoperability for Microwave Access) has been inaugurated in Bangladesh. Two companies Banglalion and Augere (Qubee) have started to provide WIMAX based wireless Internet services in the country which is gaining popularity very rapidly.

Attributes and facilities of WIMAX based and EDGE/EVDO based wireless Internet service are different. Consumers' brand choice behavior is led by different factors: product's/service's attributes is one of the most leading factors among them. The wireless Internet services in Bangladesh are basically of two types one is WIMAX based which is provided by two companies, Banglalion and Augere, another is EDGE/EVDO based which is provided by six mobile phone operators of the country. A comparative study between these two types of service may bring the key success factors of ISP (Internet Service Provider) business in light. 


\section{STATEMENT OF THE PROBLEM}

Internet is now very essential to people. Though the user ratio is very low but faster and sky-rocketing growth is knocking at the door of the industry. Most of the individual users prefer wireless Internet service to wire-based fixed line service. There are eight companies playing in the wireless Internet industry of Bangladesh. Available wireless Internet services in the country are basically of two types, WIMAX based and EDGE/EVDO based. Two companies are providing WIMAX based service and six mobile phone operators of the country are providing EDGE/EVDO based service. What are the potential attributes of interest that lead the users to choose a specific type of service? This question should be answered to force the industry to the benchmark as well as to take right repositioning strategy by the existing players of the industry. Measurement of users' service selection behavior may neutralize the problem of understanding that how the consumers make service selection decision. Which type of wireless Internet service bears more prospects to lead the industry? It should be explored to take the right entry strategy by the new players of the industry as well as to take right growth strategy by the existing players of the industry.

\section{OBJECTIVES OF THE STUDY}

The main objective of the study is to measure the comparative service choice behavior of individual users of WIMAX based and EDGE/EVDO based wireless Internet service. Some other additional objectives are also established along with the main objective and these are stated below:

1. To explore the salient attributes that lead the individual users to choose a specific type of wireless Internet service (i.e. WIMAX, EDGE/EVDO)

2. To measure the individual users' attitude towards the attributes of WIMAX and EDGE/EVDO based wireless Internet service

3. To test the hypothesis to compare differences in individual users' attitude towards WIMAX and EDGE/EVDO based wireless Internet service

4. To provide recommendations to promote the wireless Internet service industry in Bangladesh

\section{METHODOLOGY, DATA AND STUDY LIMITATIONS}

This empirical study was chiefly based on quantitative data. Both primary and secondary data were used to complete this study. Population of the study is all the individual users of wireless Internet service provided by eight companies in Bangladesh. The working population was limited to the users in Khulna and Dhaka city due to the convenience of the authors. To collect the primary data, 192 wireless Internet service users were selected as sample, 92 customers from 
WIMAX users and remaining 100 from EDGE/EVDO users. Convenient sampling technique was used to isolate the sample units from working population. Required primary data were collected from sample respondents through personal interview with a structured questionnaire. To measure the consumers' attitude towards salient attributes of wireless Internet service 5 point likert scale (C.R. Kothari 2005) was used. The foremost limitation of the study is associated with the sample size, sampling technique, and working population. 192 samples might not be enough to generalize the findings over the concerned population. Random sampling technique would have been better than convenient sampling technique, but for the researchers' easiness convenient sampling technique was used. Sample respondents were chosen from Dhaka and Khulna city only which can be considered another limitation. This study focused on the broad types of wireless Internet service (i.e. Wimax and EDGE/EVDO), not on any specific brand (i.e. Banglalion, Qubee, Grameen Phone, Citycell etc.). Specific brand may contain different status from its broad category. So further research can be carried out on the issue focusing on the specific brands.

\section{DATA ANALYSIS PROCEDURE AND PROPOSED MODEL}

To measure the consumers' attitude of wireless Internet service, Fishbein multi attribute model (Fishbein, M. 1963) was used which is symbolized as $A_{0}=\sum_{i=1}^{n} b_{i} e_{i}$. In the model $A_{0}$ refers to an overall attitude towards an object, $b_{i}$ indicates the strength of one's belief about the attribute (i) of that object and $e_{i}$ refers to the evaluation of feelings of the attributes. Along with Fishbein model mean score of each salient attribute of both types of wireless Internet services, standard deviation as well as variance were also calculated. In case of testing hypothesis, two tailed $\mathrm{Z}$ test was carried out to signify the observed differences between attitude toward WIMAX and EDGE/EVDO based Internet service. To compare between two mean, $\mathrm{Z}$ is calculated by using the formula, $Z=\frac{\overline{x_{1}}-\overline{x_{2}}}{\sqrt{\frac{s_{1}^{2}}{n_{1}}+\frac{s_{2}^{2}}{n_{2}}}}$

here $\overline{x_{1}}$ is considered as mean of beliefs towards WIMAX and $\overline{x_{2}}$ is considered as mean of beliefs towards EDGE/EVDO based Internet service. 


\section{HYPOTHESIS}

To compare the individual consumers' attitude towards WIMAX and EDGE/EVDO based wireless Internet service, the hypothesis is developed as follows:

\section{Null Hypothesis}

$H_{0}: \mu_{1}=\mu_{2}$, that means there is no significant differences between the mean of consumers' attitude towards WIMAX and EDGE/EVDO based Internet service.

\section{Alternative Hypothesis}

$H_{a}: \mu_{1} \neq \mu_{2}$, which reflects that mean of consumers' attitude towards WIMAX is not the same as consumers' attitude towards EDGE/EVDO based Internet service.

\section{RESULTS AND DISCUSSIONS}

Fishbein Multi Attributes Model was developed by Martin A Fishbein in 1963 and it was described in his publication entitled 'An investigation of the relationships between beliefs about an object and the attitude toward that object' which was published in the Journal of Human Relations, August 1963, 16: 233239. According to this model, attitudes are formed based on two basic components. One is the belief about the specific attribute of an object and another is the evaluation of feelings of the attribute of an object. In this study the salient attributes of wireless Internet could be speed, bandwidth fluctuation rate, monthly cost, price of required modem, network coverage, helpful customer care and technical support, instant query of data usage, bill payment system, etc. The Fishbein's model is formulated as below:

$$
A_{0}=\sum_{i=1}^{n} b_{i} e_{i}
$$

Where,

$A_{0}=$ Person's overall Attitude towards the object.

$b_{i}=$ The strength of one's belief about the attribute (i) or factor of an object.

$e_{i}=$ The evaluation of feelings of the attribute (i) or factor of that object.

$\mathrm{n}$ = The number of salient attributes 
The following table gives the summary of the customers' beliefs and evaluation of selected attributes of wireless Internet services.

TABLE 1

CUSTOMERS' BELIEFS AND EVALUATION

\begin{tabular}{c|l|c|c|c|c|c|c}
\hline S.L & Factors/Attributes & \multicolumn{3}{|c|}{ WIMAX } & \multicolumn{3}{c}{ EDGE/EVDO } \\
& & \multicolumn{3}{|c}{$n_{1}=92$} & \multicolumn{3}{c}{$n_{2}=100$} \\
\cline { 3 - 8 } & & $b_{i}$ & $e_{i}$ & $b_{i} e_{i}$ & $b_{i}$ & $e_{i}$ & $b_{i} e_{i}$ \\
\hline 1 & Bandwidth (Speed) & 1.39 & 1.87 & 2.60 & 0.9 & 1.60 & 1.44 \\
2 & Fluctuation rate of bandwidth & 0.52 & 0.78 & 0.41 & 0.15 & 0.98 & 0.15 \\
3 & Monthly cost & 0.47 & 1.13 & 0.53 & 0.6 & 1.30 & 0.78 \\
4 & Price of required modem & 0.91 & 0.69 & 0.63 & 0.37 & 0.97 & 0.36 \\
5 & Network coverage & 1.30 & 1.82 & 2.37 & 1.00 & 1.55 & 1.55 \\
6 & Convenient bill payment system & 0.60 & 0.91 & 0.55 & 1.47 & 1.03 & 1.51 \\
7 & Helpful customer care & 1.21 & 1.48 & 1.79 & 1.02 & 1.40 & 1.43 \\
8 & Simplicity in configuration setup & 1.00 & 1.09 & 1.09 & 1.27 & 0.95 & 1.21 \\
9 & Online instant query about data usage & 0.69 & 0.96 & 0.66 & 0.72 & 0.92 & 0.66 \\
10 & Connection sharing facilities & 1.00 & 1.09 & 1.09 & 0.57 & 1.12 & 0.64 \\
& & & & $\mathbf{1 1 . 7 1}$ & & & $\mathbf{9 . 7 3}$ \\
\hline
\end{tabular}

Source: Field Survey, February 2011

According to the model explained above with data presented in the Table 1;

Customers' overall attitude towards the selected attributes of WIMAX,

$$
\begin{aligned}
\text { Attitude wimax } & A_{0}=\sum_{i=1}^{10} b_{i} e_{i} \\
= & (1.39)(1.87)+(0.52)(0.78)+(0.47)(1.13)+(0.91)(0.69)+(1.30) \\
& (1.82)+(0.60)(0.91)+(1.21)(1.48)+(1.00)(1.09)+(0.69)(0.96) \\
& +(1.00)(1.09) \\
= & 2.60+0.41+0.53+0.63+2.37+0.55+1.79+1.09+0.66+1.09 \\
= & \mathbf{1 1 . 7 1}
\end{aligned}
$$


And customers' overall attitude towards the selected attributes of EDGE/EVDO,

$$
\begin{aligned}
\text { Attitude EDGE/EVDO } & A_{0}=\sum_{i=1}^{10} b_{i} e_{i} \\
= & (0.9)(1.60)+(0.15)(0.98)+(0.6)(1.30)+(0.37)(0.97)+(1.00)(1.55)+ \\
& (1.47)(1.03)+(1.02)(1.40)+(1.27)(0.95)+(0.72)(0.92)+(0.57)(1.12) \\
= & 1.44+0.15+0.78+0.36+1.55+1.51+1.43+1.21+0.66+0.64 \\
= & \mathbf{0 9 . 7 3}
\end{aligned}
$$

From the above calculation it indicates that customers show overall more positive attitude towards WIMAX based Internet services than EDGE/EVDO based Internet services. More specifically Banglalion and Qubee, the Wimax operators creates more positive attitude in the customers mind than six mobile phone operators in the country who also compete as the EDGE/EVDO based Internet service operator.

FIGURE 1: Comparative Customers' beliefs of WIMAX and EDGE/EVDO Internet

\section{Consumers' Attitude towards wireless internet services}

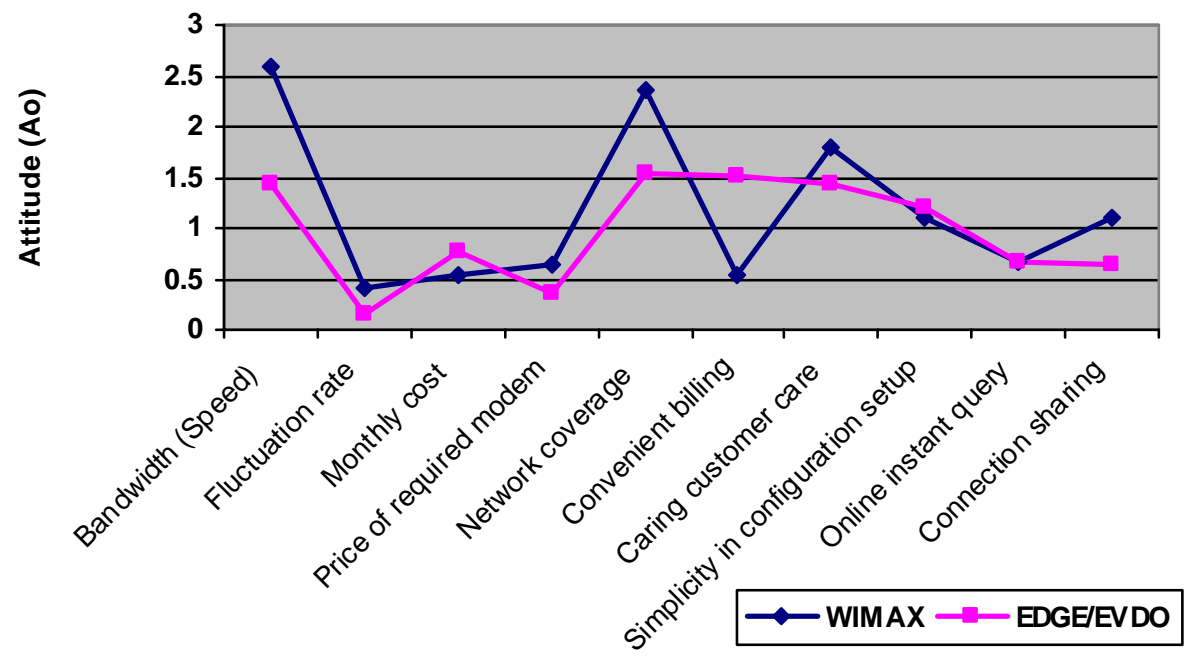

Salient Attributes of internet services 
Figure 2: Comparative customers' beliefs and evaluation of WIMAX and

\section{EDGE/EVDO}

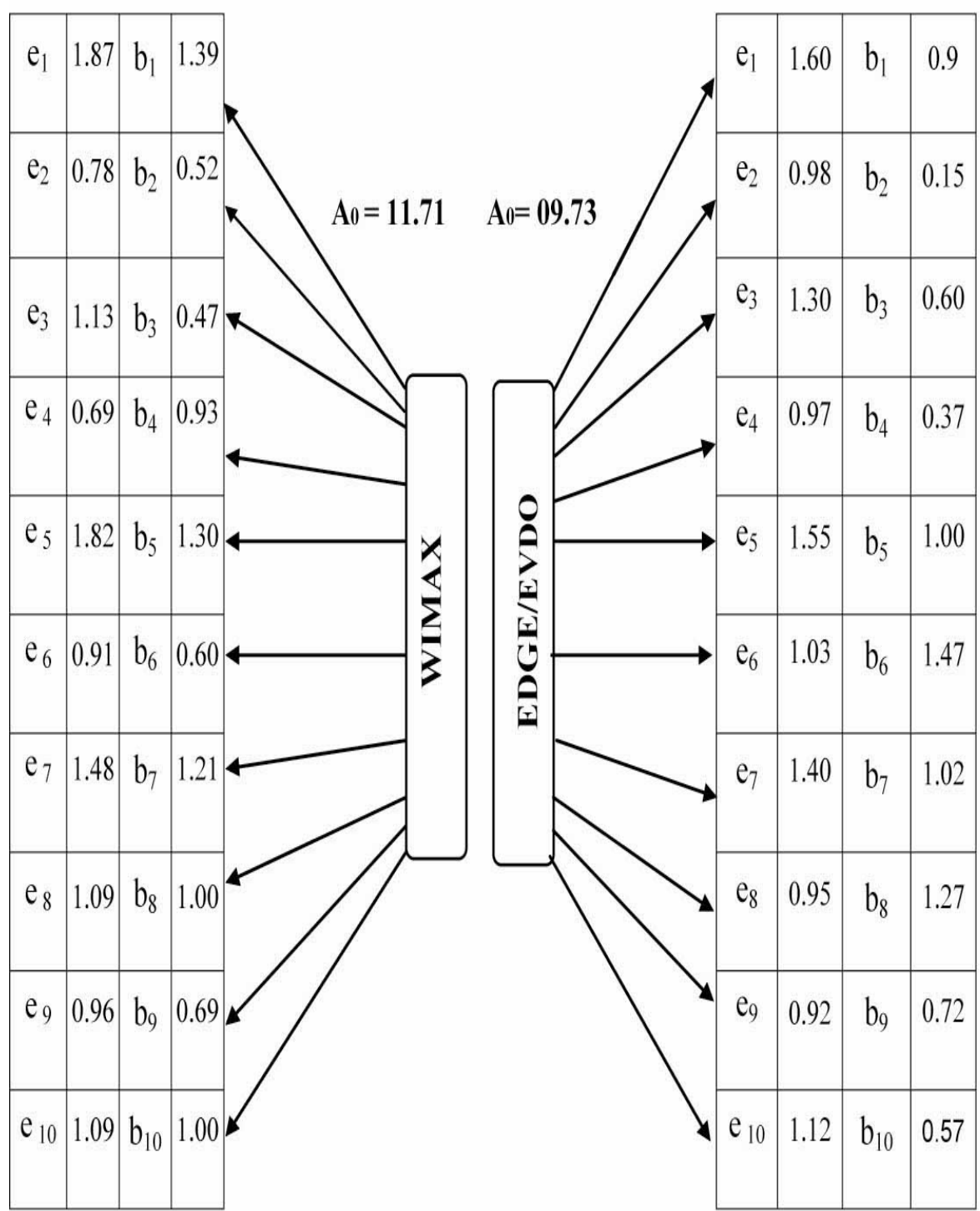


Customers' evaluation $\left(e_{i}\right)$ reflects the feeling regarding the degree of importance of a specific attribute of an object. Customers' beliefs $\left(b_{i}\right)$ indicate the actual perception of an object formulated through using experience. So we compare the customers' beliefs towards both WIMAX and EDGE/EVDO based Internet services and to measure the significance of the observed differences between the types of service $\mathrm{Z}$ test technique was used.

Comparative customers' belief between the WIMAX and EDGE/EDVO based Internet services is show in the below table.

TABLE 2

\section{HYPOTHESIS TESTS OF MEAN BELIEFS BETWEEN WIMAX AND EDGE/EVDO}

\begin{tabular}{|c|c|c|c|c|c|c|c|}
\hline \multirow[t]{2}{*}{ Attributes } & \multicolumn{2}{|c|}{ WIMAX } & \multicolumn{2}{|c|}{ EDGE/EVDO } & \multirow{2}{*}{$\begin{array}{l}\text { Computed } \\
\text { value of } Z\end{array}$} & \multirow{2}{*}{$\begin{array}{c}\text { Critical } \\
\text { value of Z } \\
\text { @ 5\% } \\
\text { significance } \\
\text { level }\end{array}$} & \multirow{2}{*}{$\begin{array}{l}\text { Result } \\
\text { (Ho) }\end{array}$} \\
\hline & Mean & $\begin{array}{c}\text { Std. } \\
\text { Deviation }\end{array}$ & Mean & $\begin{array}{c}\text { Std. } \\
\text { deviation }\end{array}$ & & & \\
\hline $\begin{array}{l}\text { Bandwidth } \\
\text { (Speed) }\end{array}$ & 1.39 & 0.706 & 0.9 & 0.994 & 4.19 & $|1.96|$ & Rejected \\
\hline $\begin{array}{l}\text { Fluctuation rate } \\
\text { of bandwidth }\end{array}$ & 0.52 & 1.137 & 0.15 & 1.130 & 2.35 & $|1.96|$ & Rejected \\
\hline Monthly cost & 0.47 & 0.972 & 0.6 & 0.916 & -0.99 & $|1.96|$ & Accepted \\
\hline $\begin{array}{l}\text { Price of required } \\
\text { modem }\end{array}$ & 0.91 & 0.653 & 0.37 & 1.017 & 4.69 & $|1.96|$ & Rejected \\
\hline $\begin{array}{l}\text { Network } \\
\text { coverage }\end{array}$ & 1.30 & 0.804 & 1.00 & 0.921 & 2.53 & $|1.96|$ & Rejected \\
\hline $\begin{array}{l}\text { Convenient bill } \\
\text { payment system }\end{array}$ & 0.60 & 1.093 & 1.47 & 0.547 & -6.99 & $|1.96|$ & Rejected \\
\hline $\begin{array}{l}\text { Caring customer } \\
\text { care }\end{array}$ & 1.21 & 0.656 & 1.02 & 0.879 & 1.80 & $|1.96|$ & Accepted \\
\hline $\begin{array}{l}\text { Simplicity in } \\
\text { configuration } \\
\text { setup }\end{array}$ & 1.00 & 0.860 & 1.27 & 0.670 & -2.49 & $|1.96|$ & Rejected \\
\hline $\begin{array}{l}\text { Online instant } \\
\text { query about data } \\
\text { usage }\end{array}$ & 0.69 & 0.905 & 0.72 & 0.836 & -0.25 & $|1.96|$ & Accepted \\
\hline $\begin{array}{l}\text { Connection } \\
\text { sharing facilities }\end{array}$ & 1.00 & 0.978 & 0.57 & 1.069 & 3.05 & $|1.96|$ & Rejected \\
\hline
\end{tabular}


The above hypotheses are tested by using the technique of $\mathrm{Z}$ test regarding the differences between two means. The computed $\mathrm{Z}$ values of the Table are determined by using formula:

$$
Z=\frac{\overline{x_{1}}-\overline{x_{2}}}{\sqrt{\frac{s_{1}^{2}}{n_{1}}+\frac{s_{2}^{2}}{n_{2}}}}
$$

Where,

$$
\begin{aligned}
& Z=\text { Calculated value } \\
& \overline{x_{1}}=\text { The mean value of the attribute of WIMAX } \\
& \overline{x_{2}}=\text { The mean value of the attribute of EDGE/EVDO } \\
& s_{1}=\text { The standard deviation of the attribute of WIMAX } \\
& s_{2}=\text { The standard deviation of the attribute of EDGE/EVDO } \\
& n_{1}=\text { Sample size of WIMAX users } \\
& n_{2}=\text { Sample size of EDGE/EVDO users }
\end{aligned}
$$

At $5 \%$ level of significance, the critical value of $\mathrm{Z}$ for two tailed test is \pm 1.96. If the computed value of $Z$ is greater than +1.96 or less than -1.96 , then $H_{0}$ is rejected otherwise $\mathrm{H}_{\mathrm{a}}$ is rejected or $\mathrm{H}_{0}$ is accepted.

From the above table, it is found that $\mathrm{H}_{0}$ is accepted against only 3 attributes, monthly cost, customer care service and online data usage query respectively among the 10 attributes and $\mathrm{H}_{0}$ is rejected against the remaining 7 attributes. That means, there is no difference between customers' attitude of WIMAX and EDGE/EVDO based Internet service regarding the 3 salient attributes but there are significant differences between the same regarding remaining 7 attributes. More specifically consumers' attitude is more positive towards WIMAX regarding Bandwidth (Speed), low fluctuation rate of band width, price of required modem, network, simplicity in configuration setup or driver installation, and connection sharing facilities than EDGE/EVDO based Internet services. On the other hand consumers' attitude is more positive towards EDGE/EVDO regarding only convenient bill payment and recharge system than WIMAX based Internet services. And customers show the equal attitude towards the regarding monthly service usage cost, customer care service, and online instant query about data usage.

In case of cost for monthly service usage and instant query about data usage; customers' attitude towards both types of operators below satisfaction level. 


\section{CONCLUSIONS AND RECOMMENDATIONS}

On the basis of overall customer attitude found in this research; EDGE/EVDO based Internet service operators (i.e. six mobile phone operators of the country) should improve their services to compete with WIMAX operators. Banglalion and Qubee (Wimax operator) should improve their bill payment and recharge system to make it more convenient to the customers. EDGE/EVDO based operators should increase bandwidth (speed) of their service, reduce the bandwidth fluctuation rate, they should also expand the connection sharing facilities as now it is a common state of affairs that a single household uses more than one computer. The price of EDGE/EVDO compatible modem is higher than WIMAX based modem according to the customers' belief, so EDGE/EVDO operators should sell the required modems at lower prices. Even they can provide it free of cost to the new customers against a long term service using contract.

\section{REFERENCES}

Allison R. Johnson and David W. Stewart, 2005, "A Reappraisal of the Role of Emotion in Consumer Behavior" Review of Marketing Research, Volume 1, Prentice-Hall of India.

Alom, M.J. and Neger. Meher, 2009, "Measuring Consumer Attitude towards Beautification Products: A Study on Some selected Brands in Bangladesh." Journal of Business and Technology (Dhaka), 4(2),: 61.

Anton (2011), "Factor Affecting Users' Choice of Mobile Phone Operator: A Study on Bangladesh Perspective”, Essays24.com, $1^{\text {st }}$ January, http://essays24.com/ print/Paper-On-Survey-On-Mobile/27725.html, retrieved on 4th April 2011 at 3:05 pm.

Gupta, S.P. and Gupta, M.P. Business Statistics, Fourteenth edition, 2006-2007.

Hamidur (2009), "Internet History of Bangladesh", Wireless Bangladesh, April 08, http://wirelessbangladesh.blogspot.com/2009/04/Internet-history-of-bangladesh. html, retrieved on 2nd April 2011 at 5:50 pm.

Haque. Ahsanul, Nuruzzaman and Kalam. Abul (2011), "Customer Satisfaction of Mobile Phone Services: An Empirical Study on Grameen Phone (GP) and Banglalink (BL) in Bangladesh”, Journal of International Business Management, Volume 05, Issue 03, 140-150.

Internet World Stats Usage and Population, http://www.Internetworldstats.com/asia/bd. htm, retrieved on $26^{\text {th }}$ March 2011 at 8:15 pm.

Kothari, C.R. (2005), Research Methodology, Methods and Techniques, Second Edition, New Age International Publishers, New Delhi.

Martin Fishbein (1963), An Investigation of the Relationship between Beliefs about an object and the attitude towards that object, Human Relations, August 16, 233-240.

Mittal, vikas, William T. Toss, jr. and Patrick M. Balasare (1998),"The Asymmetric Impact of Negative and Positive Attribute-level Performance on Overall 
Satisfaction and Repurchase Intentions," Journal of Marketing, 62(January),: 33-47.

Rahman, Md. Fazlur (2011) "Grow up with WIMAX”, The Daily Star, March 01, http://www.thedailystar.net/newDesign/news-details.php?nid=175898, retrieved on 2nd April 2011 at 3:25 pm.

Wikipedia, http://en.wikipedia.org/wiki/WiMAX, retrieved on 2nd April 2011 at 3:50 pm

Wikipedia, http://en.wikipedia.org/wiki/Enhanced_Data_Rates_for_GSM_Evolution, retrieved on 2nd April 2011 at 4:30 pm.

Wikipedia, http://en.wikipedia.org/wiki/Evolution-Data_Optimized, retrieved on 2nd April 2011 at 5:10 pm.

World Bank's World Development Indicator Report on Internet users as percentage of population, http://data.worldbank.org/indicator/IT.NET.USER.P2 retrieved on $28^{\text {th }}$ March 2011 at 4:10 pm. 